\title{
O ensino de pensamento computacional como inclusão tecnológica e motivação de crianças.
}

\author{
Guilherme Carvalho Rodrigues, Laureane Pereira de Sousa
}

\author{
Instituto Federal de Brasília - Campus Taguatinga (IFB) - Brasília, DF - Brazil \\ guilherme.carvalhordhotmail.com, pslaureanelgmail.com
}

\begin{abstract}
This paper is about the realization of a deployment of computational thinking with children from 8 to 12 years old. Objectifying to motivate them to develop cognitive aspects and to promote technological inclusion. Toward to be able to understand the concepts presented, the course was developed with two methodologies: Umplugged Computing and Code.org. The results indicates that the insertion of this strategy in the school routine will help children in the capacity of abstraction and problem solving.

Resumo. Este artigo trata sobre a realização de uma oficina de fundamentos do pensamento computacional realizada com crianças de 8 a 12 anos com o objetivo de motivá-las a desenvolverem aspectos cognitivos e promover a inclusão tecnológica. Para que fosse possível a compreensão dos conceitos apresentados, o curso foi desenvolvido com duas metodologias: a Computação Desplugada e o Code.org. Os resultados apontam que a inserção desta estratégia no cotidiano escolar ajudará na capacidade de abstração e de resolução de problemas.
\end{abstract}

\section{Introdução}

Os nascidos depois dos anos 2000 são considerados nativos digitais, pois nasceram quando as tecnologias digitais já estavam popularizadas, sendo fácil ter acesso a elas. Eles entendem a informação de forma diferente, suas experiências e interações sociais ocorrem mais no mundo virtual que no mundo físico, sendo que a identidade pessoal é construída pelas características pessoais, interesses e atividades. (PALFREY E GASSER, 2011).

$\mathrm{Na}$ Era Digital a quantidade de informações compartilhadas gira em torno de bilhões de gigabytes disponíveis na rede, entretanto quanto é possível absorver dessas informações em termos cognitivos ou com que qualidade elas são compreendidas?

É importante desenvolver os fundamentos da computação em crianças que vivem em sociedades que tenham esse perfil, pois o uso deles implica novas formas de pensar e pode auxiliar aqueles que possuem dificuldades de aprendizagem e possibilitar a sua inclusão tecnológica. Costa (2012) afirma que o público infantil possui contato com máquinas e seus recursos, mas não detém conhecimento de conceitos da área da Computação. Considerando isso, formulou-se uma proposta de curso que pudesse desenvolver fundamentos da computação em crianças de 8 a 12 anos. 
VI Congresso Brasileiro de Informática na Educação (CBIE 2017)

Anais do XXVIII Simpósio Brasileiro de Informática na Educação (SBIE 2017)

\section{Metodologia}

Para desenvolver o curso, trabalhou-se com duas metodologias: a Computação Desplugada e o Code.org. Essas metodologias foram adotadas por possuírem um caráter lúdico, com objetivos claros e atividades em forma de desafios.

Os conceitos computacionais podem ser ensinados sem que se utilize um computador, por meio de atividades fundamentadas nas áreas de Tecnologia e Matemática, por meio da Computação Desplugada, cujo objetivo é ensinar independente de recursos de hardware ou software (BELL, WITTEN E FELLOWS, 2011). Costa (2012) apresenta uma experiência de ensino baseada na metodologia da computação desplugada e aponta, como resultado, a melhoria na assimilação de conteúdos da computação e a fluência nas questões relacionadas à organização do pensamento.

A plataforma utilizada foi o Code.org, que pertence à Instituição Code.org, uma organização sem fins lucrativos que tem como principal objetivo a disseminação e o ensino de lógica de programação a pessoas de todas as idades. Ela visa ensinar de forma lúdica, interativa e compreensível os conceitos da área da computação.

As atividades propostas para serem desenvolvidas pelos alunos do curso foram organizadas em três unidades: i) algoritmos; ii) lógica de programação; iii) detecção e correção de erros. Buscou-se, por meio delas, desenvolver a criatividade para a resolução de problemas, estimulando a interação e o trabalho colaborativo, bem como a autonomia em relação ao uso do computador como forma de empoderamento.

O curso contou com uma base comum e, em cada aula, havia dois regentes responsáveis pelas atividades e seis tutores. As aulas foram organizadas em três momentos: no primeiro, foram desenvolvidas atividades de computação desplugada; no segundo, as atividades foram desenvolvidas no Code.org; e por fim foram sugeridas atividades para casa no Code.org.

\section{Análise das experiências}

Tarouco et. al. (2004) afirmam que a utilização de jogos como ferramentas são eficientes, pois eles são mais divertidos e motivadores, facilitando a aprendizagem e aumentando a capacidade retentiva dos conceitos ensinados, bem como o exercício das funções mentais do jogador.

Os exercícios realizados em sala de aula pela ferramenta Code.Org entregam um problema lógico para o aluno e fazem com que ele reflita sobre estes e busquem solucioná-los, interagindo com o problema apontado e com a implementação do seu pensamento no computador. As crianças, de forma geral, alcançaram esses objetivos. Para chegar a essa conclusão, foram utilizadas as anotações do diário de bordo dos monitores e as informações oriundas do monitoramento dos estudantes na plataforma, o que permitiu um acompanhamento personalizado.

As principais dificuldades encontradas com a realização das atividades em laboratório foram os conhecimentos prévios como, por exemplo, a lateralidade e a falta de habilidades como localização espacial, atenção e abstração. 
As crianças que tiveram maiores dificuldades no decorrer do curso foram as que não fizeram as atividades propostas para serem realizadas em casa. No decorrer do curso, verificou-se ainda a existência de crianças com Distúrbio do Processamento Auditivo Central (DPAC). Diagnosticado isso, optou-se por colocar um tutor para acompanhamento de cada criança com necessidade específica.

Notou-se também a falta de atenção, concentração e motivação de alguns alunos. Para Knüppe (2006), no processo ensino-aprendizagem, a motivação deve estar presente em todos os momentos. Partindo desse princípio, pode-se afirmar que essas faltas citadas incidiram diretamente no desempenho, comprometendo, assim, o processo de ensino-aprendizagem dos referidos alunos. Apesar disso, esses alunos buscavam interagir com os outros colegas durante as dinâmicas e atividades realizadas

\section{Conclusão}

Percebeu-se que as estratégias adotadas auxiliaram os alunos a desenvolver maior nível de abstração e de resolução dos exercícios, apresentando resultados satisfatórios nesse quesito; ademais, os participantes puderam materializar seus pensamentos em novas linguagens, transformando as informações em conhecimento. Além disso, fazer e refazer atividades modificou o conceito de erro, que passou a ser reconhecido como relevante para a produção de novos saberes.

Assim, recomenda-se que essas estratégias sejam desenvolvidas em escolas de educação básica como atividades complementares para ampliar a capacidade de abstração e de resolução de problemas.

\section{Referências}

Bell, T.; Witten, I. H.; Fellows, M. (2011) Computer Science Umplugged: Ensinando Ciência da Computação sem o uso do computador. Traduzido por Luciano Porto Barreto. Disponível em csunplugged.org

Costa, T.; Batista, A.; Maia, M.; Almeida, L.; Farias, A. (2012) Trabalhando Fundamentos de Computação no Nível Fundamental: experiência de licenciandos em Computação da Universidade Federal da Paraíba. In: Workshop sobre Educação em Computação - WIE, 20. Curitiba

Knüppe, Luciane. (2006) Motivação e desmotivação: desafios para as professoras do Ensino Fundamental. Educar, Curitiba, n. 27, p. 277-290. Editora UFPR.

Palfrey, John; Gasser, Urs (2011) Nascido na era digital, entendendo a primeira geração de nativos digitais. Tradução: Magda França Lopes. Porto Alegre, Grupo A.

Tarouco, L. M. R.; Roland, L. C.; Fabre, M. C. J. M.; Konrath, M. L. P. (2004) Jogos educacionais. In: Novas Tecnologias na Educação - RENOTE, v.2, n.1. 